\title{
A morphometric study of the progressive changes on NADPH diaphorase activity in the developing rat's barrel field
}

\author{
Marco Aurélio M. Freire ${ }^{\mathrm{a}}$, Walace Gomes-Leal ${ }^{\mathrm{a}}$, Walther A. Carvalho ${ }^{\mathrm{a}}$, \\ Joanilson S. Guimarães ${ }^{\mathrm{a}}$, João G. Franca ${ }^{\mathrm{c}}$, Cristovam W. Picanço-Diniz ${ }^{\mathrm{a}, *}$, \\ Antonio Pereira Jr. ${ }^{\text {b, } 1}$ \\ ${ }^{a}$ Laboratory of Functional Neuroanatomy, Department of Morphology, Federal University of Pará, 66075-900 Belém, PA, Brazil \\ ${ }^{\mathrm{b}}$ Department of Physiology, Federal University of Pará, 66075-900 Belém, PA, Brazil \\ ${ }^{\mathrm{c}}$ Institute of Biophysics Carlos Chagas Filho, Federal University of Rio de Janeiro, Rio de Janeiro, RJ, Brazil
}

Received 25 March 2004; accepted 27 May 2004

Available online 2 July 2004

\begin{abstract}
The distribution of NADPH diaphorase (NADPH-d)/nitric oxide synthase (NOS) neurons was evaluated during the postnatal development of the primary somatosensory cortex (SI) of the rat. Both cell counts and area measurements of barrel fields were carried out throughout cortical maturation. In addition, NADPH-d and cytochrome oxidase (CO) activities were also compared in both coronal and tangential sections of rat SI between postnatal days (P) 10 and 90. Throughout this period, the neuropil distributions of both enzymes presented a remarkable similarity and have not changed noticeably. Their distribution pattern show the PMBSF as a two-compartmented structure, displaying a highly reactive region (barrel hollows) flanked by less reactive regions (barrel septa). The number of NADPH-d neurons increased significantly in the barrel fields between P10 and P23, with peak at P23. The dendritic arborization of NADPH-d neurons became more elaborated during barrel development. In all ages evaluated, the number of NADPH-d cells was always higher in septa than in the barrel hollows. Both high neuropil reactivity and differential distribution of NADPH-d neurons during SI development suggest a role for nitric oxide throughout barrel field maturation.
\end{abstract}

(C) 2004 Elsevier Ireland Ltd and The Japan Neuroscience Society. All rights reserved.

Keywords: Somatosensory cortex; Barrel field; PMBSF; NADPH diaphorase; Nitric oxide; Cytochrome oxidase; Cortical development; Rat

\section{Introduction}

In mammals, specializations of the sensory periphery influence the organization of the central nervous system (CNS) during development, sculpting sensory maps which reflect the distribution and diversity of receptors (Killackey et al., 1995). In the isocortex, cells in sensory areas are normally organized in a columnar fashion from pial surface to white matter, effectively breaking up the peripheral representation into a mosaic of processing modules (Mountcastle, 1997).

\footnotetext{
* Corresponding author. Tel.: +55 91211 1741; fax: +55 912111741.

E-mail address: leal@ufpa.br (C.W. Picanço-Diniz).

${ }^{1}$ Present address: Department of Neurobiology, Box 3209101 Research Drive Bryan Research Building, Duke University Medical Center, Durham, North Carolina 27710.
}

In some small rodents, this modular organization is most evident in layer IV of the primary somatosensory cortex (SI), where cell aggregates, aptly called barrels, are found (Woolsey and van der Loos, 1970; Welker, 1971; van der Loos and Woolsey, 1973). Individual barrels aggregate to form regular arrays in the somatosensory cortex representing the entire contralateral periphery (see Rice, 1995 for review). The largest barrels are located at the posteromedial barrel sub-field (PMBSF) and are neatly organized in rows which reproduce the organization of the mystacial vibrissae, a highly specialized tactile organ (Glassman, 1994).

Since barrels are regions with high metabolic rates (Melzer and Smith, 1998), they can be easily identified by simple histochemical techniques that reveal the activity of metabolic enzymes such as succinic dehydrogenase (SDH) and cytochrome oxidase (CO) (Wallace, 1987). CO is a key enzyme in the final steps of oxidative metabolism 
(Wong-Riley, 1989). The analysis of its distribution throughout the nervous system has allowed the discrimination of individual brain areas and the identification of modules within some of them (Wong-Riley, 1989). In the rodent barrel field, $\mathrm{CO}$ activity is first detected around postnatal day 4 (P4), with a pattern very similar to the classical Nissl stain in adult animals and has been used as a trustworthy method to reveal the organization and morphology of barrel field (Wong-Riley and Welt, 1980; Vercelli et al., 1999).

Since the early 1960's it has been known that the enzyme nicotinamide adenine dinucleotide phosphate diaphorase (NADPH-d) reveals a selective neuronal sub-population of interneurons (Thomas and Pearse, 1961). Lately, it has been described a co-localization between NADPH-d and nitric oxide synthase (NOS) in this neuronal sub-population (Hope et al., 1991; Dawson et al., 1991; Luth et al., 1995). NOS is the neuronal enzyme responsible for the synthesis of nitric oxide (NO), a highly diffusible molecule involved in several physiological and pathological processes in the CNS (Iadecola, 1993; Wallace et al., 1996; Estevez et al., 1998; see Contestabile, 2000 for review). Accordingly, several groups have effectively used NADPH-d histochemistry as an indirect method for revealing the distribution of NO in the CNS, especially in fixed tissue (Matsumoto et al., 1993).

NADPH-d histochemistry/NOS immunohistochemistry reveals two subtypes of neurons (Luth et al., 1994). Type I neurons are intensely stained. In addition, they possess large cell bodies and a rich pattern of dendritic arborization. These cells comprise about $2 \%$ of the entirety of cortical neurons (Gabbott and Bacon, 1995). Type II neurons, on the other hand, are generally more numerous and faintly stained. Contrary to Type I cells, they have small cell bodies and few or no labelled processes (Sandell, 1986; Luth et al., 1994; Yan and Garey, 1997). The presence of Type I neurons was described in virtually all species studied so far, but Type II cells seems to be absent in lower vertebrates (Luebke et al., 1992).

Numerous studies have investigated the distribution of NADPH-d neurons in different regions of the developing and adult rat CNS (Vincent and Kimura, 1992; González-Hernandez et al., 1993; Tomic et al., 1994;
Samama et al., 1995; Yan et al., 1994; Bravo et al., 1997; Yan and Garey, 1997; Franca et al., 2000; Murata and Masuko, 2003), since NO has been implicated with some aspects of cortical development (Harsanyi and Friedlander, 1997; Zhang et al., 2002). In adult animals, our group has been successful in using the activity of the NADPH-d as a marker for barrels in both rat (Franca and Volchan, 1995) and mouse (Pereira et al., 2000). Nevertheless, few studies have been carried out in the rat SI during development in order to evaluate the NADPH-d neuropil reactivity and cell distribution in the barrel field during its maturation (Vercelli et al., 1999).

In the present study, we investigated, both qualitatively and quantitatively, the tangential distribution of strongly-reactive NADPH-d (type I) neurons in SI and the neuropil pattern throughout the postnatal development of the rat brain in order to assess the temporal evolution of NADPH-d histochemical activity during barrel field maturation.

\section{Materials and methods}

\subsection{Animals}

Wistar albino rats $(n=34)$, obtained from the animal colony raised at Federal University of Pará, were used in the present work (Table 1). All efforts were made to avoid animal suffering and to reduce the number of animals used. No alternatives to in vivo techniques were available to perform this study. All experimental procedures were in accordance with NIH guidelines for the care and use of laboratory animals.

\subsection{Perfusion and histological procedures}

The animals were deeply anaesthetized with a mixture of xylazine chloridrate $(4 \mathrm{mg} / \mathrm{kg})$ and ketamine chloridrate (46 mg/kg, i.m.) and perfused through the left ventricle with $0.9 \%$ heparinized-saline, followed by $1-2 \%$ paraformaldehyde (Sigma Company, USA) in $0.1 \mathrm{M}$ phosphate buffer (PB), pH 7.4. After craniotomy, brain hemispheres were

Table 1

Summary of animals and procedures used in the present study

\begin{tabular}{|c|c|c|c|c|}
\hline Postnatal age & Number of animals & Section plane & Thickness $(\mu \mathrm{m})$ & Histological technique $^{a}$ \\
\hline P10 & 04 & Tangential/coronal & 100 & NADPH-d/CO \\
\hline P14 & 04 & Tangential/coronal & 100 & NADPH-d/CO \\
\hline P18 & 04 & Tangential/coronal & 100 & NADPH-d/CO \\
\hline $\mathrm{P} 23$ & 04 & Tangential/coronal & 100 & NADPH-d/CO \\
\hline $\mathrm{P} 25$ & 04 & Tangential/coronal & 100 & NADPH-d/CO \\
\hline P29 & 04 & Tangential/coronal & 100 & NADPH-d/CO \\
\hline P31 & 04 & Tangential/coronal & 100 & NADPH-d/CO \\
\hline P90 & 04 & Tangential/coronal & 100 & NADPH-d/CO \\
\hline P90 & 02 & Coronal & 50 & NADPH-d/NOS \\
\hline
\end{tabular}

${ }^{\text {a }}$ In the tangential sections, CO histochemistry was carried out in contralateral hemispheres. In the coronal plane, CO was made in alternate sections reacted for NADPH-d. 
flattened between two glass slides and immersed in PB overnight. The flattened brains were cut tangentially in $100 \mu \mathrm{m}$ thick sections using a vibratome (Pelco International, Series 1000). In some P90 hemispheres, coronal sections were cut $50 \mu \mathrm{m}$ thick for double staining with NADPH-d and NOS immunocytochemistry (see Table 1).

\subsection{NADPH-d histochemistry}

To reveal NADPH-d activity, brain sections were collected and washed three times in PB and incubated, free-floating, in a solution containing $0.6 \%$ malic acid, $0.03 \%$ nitroblue tetrazolium, $1 \%$ dimethylsulfoxide, $0.03 \%$ manganese chloride, $0.5 \% \beta$-NADP and $1.5-3 \%$ Triton X-100 in $0.1 \mathrm{M}$ TRIS buffer, pH 8.0 (modified from Scherer-Singler et al., 1983). The histochemical reaction was monitored every $30 \mathrm{~min}$ to avoid overstaining. Sections were incubated at the same time and in the same solution for all animals. The incubation time ranged from 3 to $4 \mathrm{~h}$ for all ages evaluated and was usually interrupted by rinsing sections in $\mathrm{PB}$ (pH 7.4). The presence of strongly labeled NADPH-d cells throughout the barrel field was required to interrupt the reaction.

\subsection{Immunocytochemistry}

In order to evaluate the relationship between NADPH-d and NO in the barrel field, NOS immunocytochemistry was performed in some sections previously reacted for NADPH-d. These sections were washed three times in $0.1 \%$ PB saline (PBS)/Tween and incubated in 10\% normal goat serum in PBS for $1 \mathrm{~h}$. After that, sections were incubated in mouse anti-NOS primary antibody (dilution at 1:150 in PBS, Serotec, UK) for about $48 \mathrm{~h}$ at $10^{\circ} \mathrm{C}$, washed three times in PBS/Tween and incubated in biotynilated goat anti-mouse secondary antibody (dilution at 1:200 in PBS, Serotec, UK) for about $1 \mathrm{~h}$. Free-floating sections were then washed three times in PBS/Tween, and incubated at room temperature under constant agitation in a solution containing two drops of A and B solutions of Elite ABC Kit (Vector Laboratories) per $10 \mathrm{ml}$ of histochemical incubation media for $1 \mathrm{~h}$. In this report, we used the DAB/Nickel method for revealing the antibody presence in the tissue, as described elsewhere (Shu et al., 1988; Gomes-Leal et al., 2002).

\subsection{Cytochrome oxidase histochemistry}

The CO histochemistry was used as a benchmark of the relative position and organization of the barrel field in all ages evaluated. In order to reveal CO activity (Wong-Riley, 1979) in both coronal (adjacent sections containing the barrel fields) and tangential brain sections (contralateral hemispheres) were incubated free-floating in a solution containing $0.05 \%$ diaminobenzidine (DAB), $0.03 \%$ cytochrome $c$ and $0.02 \%$ catalase in $0.1 \mathrm{M}$ PB. The CO histochemical reaction was monitored every 30 minutes in order to avoid overstaining. Similar to NADPH-d histochemistry, sections were incubated at the same time and in the same solution for all animals. The duration of the incubation ranged from 7 to $8 \mathrm{~h}$ for all ages evaluated and was usually interrupted by rinsing sections five times in $0.1 \mathrm{M} \mathrm{PB}(\mathrm{pH}$ 7.4). All reagents were purchased from Sigma Company, USA. Sections were mounted in gelatin-coated glass slides, left to air-dry overnight, dehydrated and coverslipped with Entellan (Merck, Germany).

\subsection{Qualitative and quantitative analyses}

A complete reconstruction of the PMBSF, revealed by NADPH-d histochemistry, with the relative position of NADPH-d type I neurons in the barrel field was made using the software Neurolucida (MicroBrightField Inc., USA). For each age evaluated (Table 1), three $100 \mathrm{~mm}$ thick tangential sections at the level of the barrel fields per animal ( $n=3$ animals per postnatal age) were reconstructed and superimposed using the blood vessels as landmarks. This procedure allowed complete reconstructions of the PMBSF. Since reactive neuropil forms barrels across approximately $300 \mu \mathrm{m}$ vertically in sections from the intermediate levels of the gray matter (Zilles and Wree, 1985), we were able to enfold the entire barrel height in three $100 \mu \mathrm{m}$ thick sections.

The PMBSF areas of rats of different ages were measured using an image processing software (Scion Image for Windows, version Beta 4.0.1, Scion Corporation, USA) based in the complete reconstructions made in Neurolucida. First, the outermost limits for the PMBSF were delineated in order to calculate the total PMBSF area. The area for each individual barrel was also measured. The area occupied by septa was obtained for the difference between the total PMBSF area and the sum of all individual barrel areas.

The relative position of the NADPH-d neurons in the PMBSF was plotted in the same nine tangential sections per age (three per animal), in which the PMBSF has been previously reconstructed to further quantitative analysis. This approach enabled us, based in the complete reconstructions of the PMBSF through layer IV, evaluate the distribution of the total number of NADPH-d type I neurons in the entire barrel field.

We performed counts of the number of these plotted cells in all reconstructed sections for the different developmental stages (P10, P23, P31 and P90) in order to quantitatively evaluate their distribution during cortical maturation. Comparisons between different groups were assessed by analysis of variance (ANOVA) with Newman-Keuls post hoc test at 95\% $(P<0.05)$ confidence level. Comparisons between the numbers of NADPH-d neurons (septa versus barrels) in each group were assessed by Student's $t$-test at $95 \%$ confidence level $(P<0.05)$. 
$\mathrm{CO}$
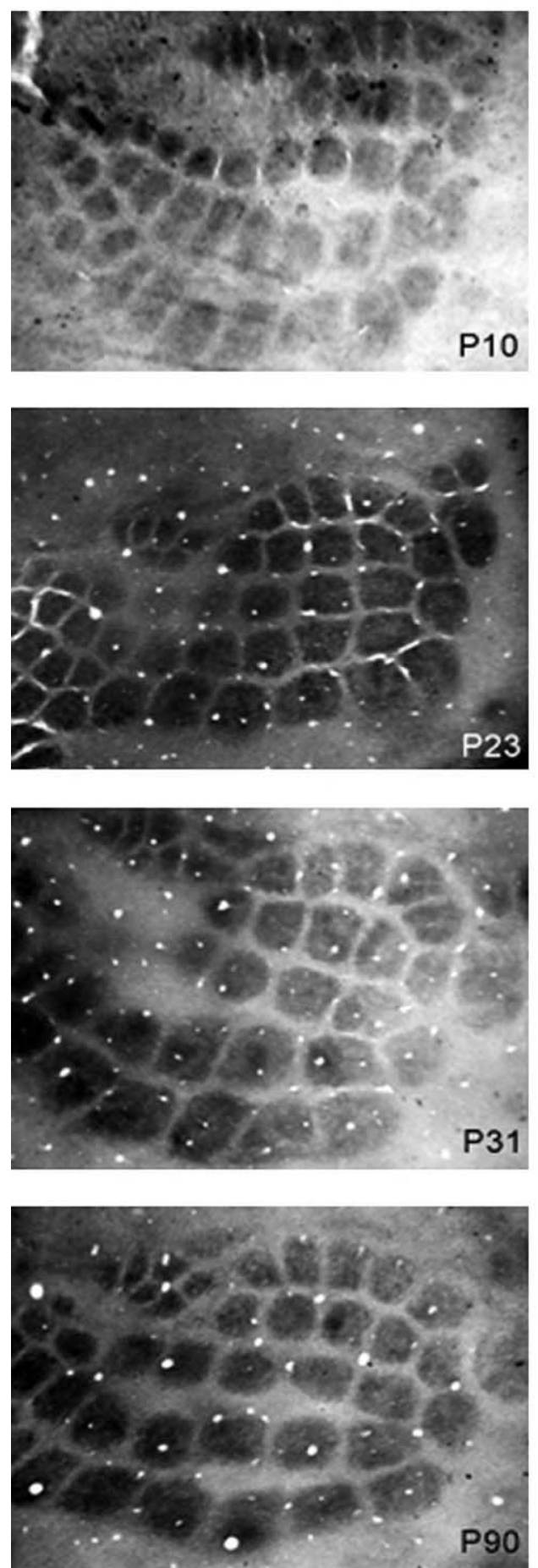

NADPH-d
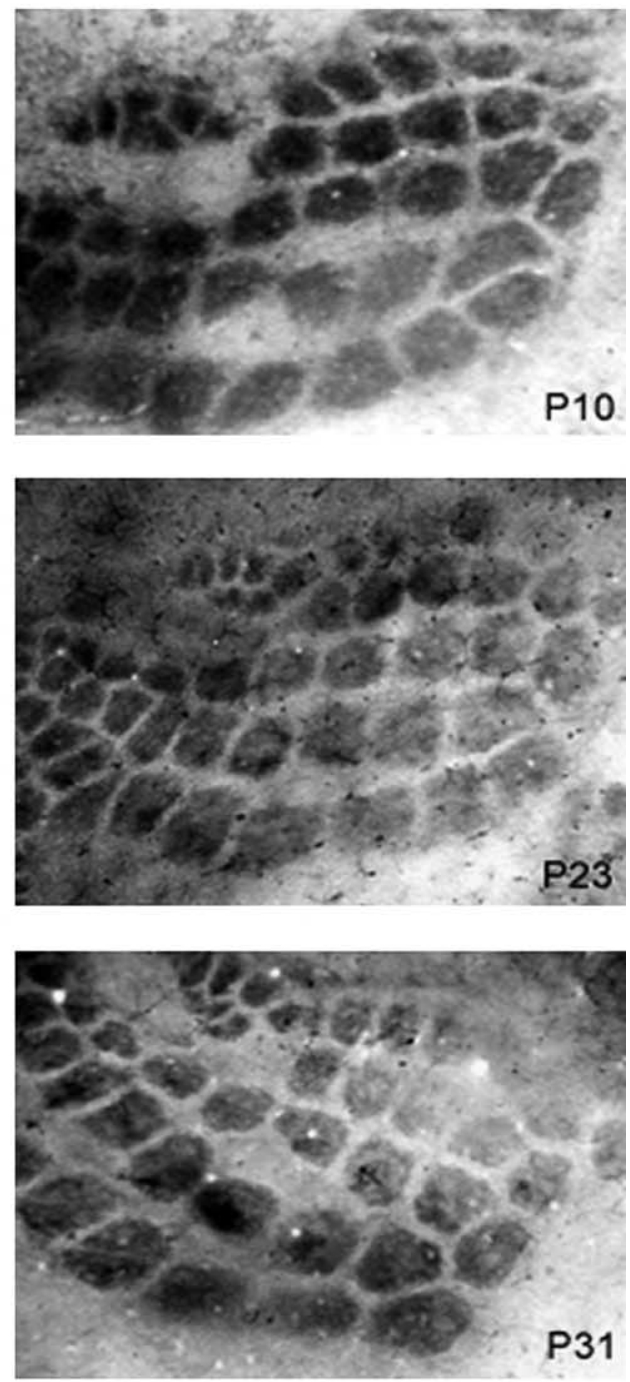

P31

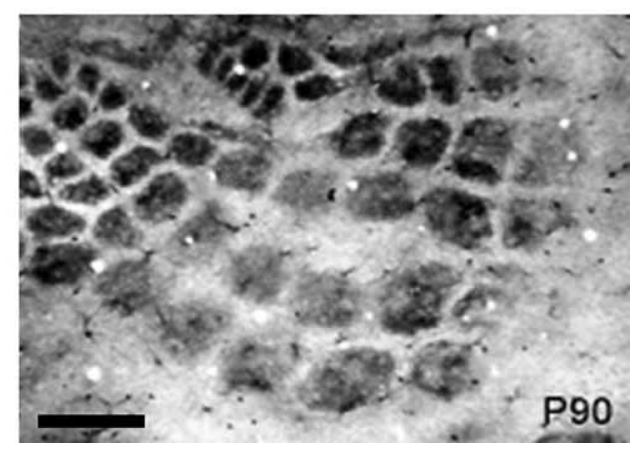

Fig. 1. NADPH-d (right column) and CO (left column) reactivities during PMBSF development. Both enzymes are non-uniformly distributed in the PMBSF, being more reactive inside barrels, which are flanked by regions of weaker reactivity (septa). Note that the distribution of both enzymes is markedly similar and seems not to change during barrel field maturation. In all ages, sections reacted to CO were obtained from contralateral hemisphere of the same animal. Scale bar: $400 \mu \mathrm{m}$. Orientation: up, lateral; right, posterior. 


\section{Results}

\subsection{Postnatal development of the barrel field dimensions revealed by $\mathrm{CO}$ and $\mathrm{NADPH}-\mathrm{d}$ histochemistries}

The barrel field and all its compartments (especially the PMBSF) could be easily identified using both NADPH-d and $\mathrm{CO}$ histochemistries (Fig. 1) in all ages analyzed. Both enzymes are unevenly distributed in the PMBSF (Fig. 1), being more intense inside barrels, which are flanked by regions of weaker reactivity (septa).

The quantitative analysis performed on the Neurolucida reconstructions (Fig. 2) revealed a progressive increase in the total PMBSF area from P10 to P31 (Fig. 3A). From P31, the total PMBSF area remained stable and was not significantly smaller than that in P90 (Fig. 3A). The quantitative analysis of total individual barrel area and septal area revealed a trend similar to that previously reported for the total PMBSF
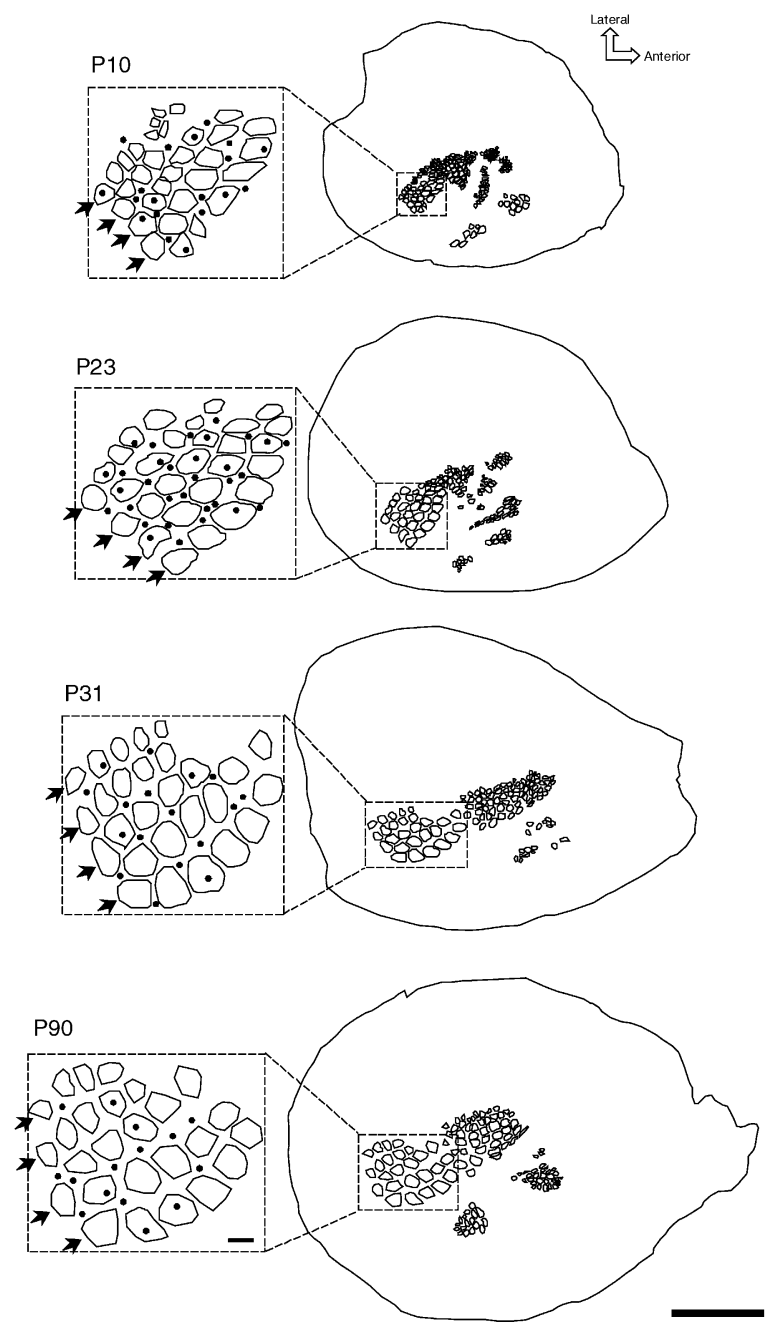

Fig. 2. Neurolucida reconstructions of PMBSF during development. The number of NADPH-d cells in the septal region is higher than inside barrels for all ages evaluated (black dots). Arrows point to the four straddlers next to the five PMBSF barrel rows. Scale bars: $2 \mathrm{~mm}$ (lower magnification drawings); $300 \mu \mathrm{m}$ (enlargements). area (Fig. 3B). Additionally, total individual barrel area did not differ $(P>0.05)$ from septal area in any of the ages analyzed (Fig. 3B). Our results regarding the increase in the rat PMBSF area are in agreement with previous reports in the mouse barrel field (Rice and van der Loos, 1977).

\subsection{Laminar distribution and morphology of NADPH-d neurons during postnatal barrel field development}

The laminar distribution of both CO and NADPH-d did not change significantly during the postnatal development (data not illustrated). In a coronal view, both CO- and NADPH-d-reactive neuropil had virtually the same laminar pattern (Fig. 4). Layer I appears as a band of moderate reaction. In layers II-III, the neuropil displayed a higher reactivity and it was rather difficult to determine the limit between the two layers. In layer IV, both NADPH-d and $\mathrm{CO}$ revealed the presence of barrels and septa, as described elsewhere (Franca and Volchan, 1995; Vercelli et al., 1999). Layer V was characterized as a region of
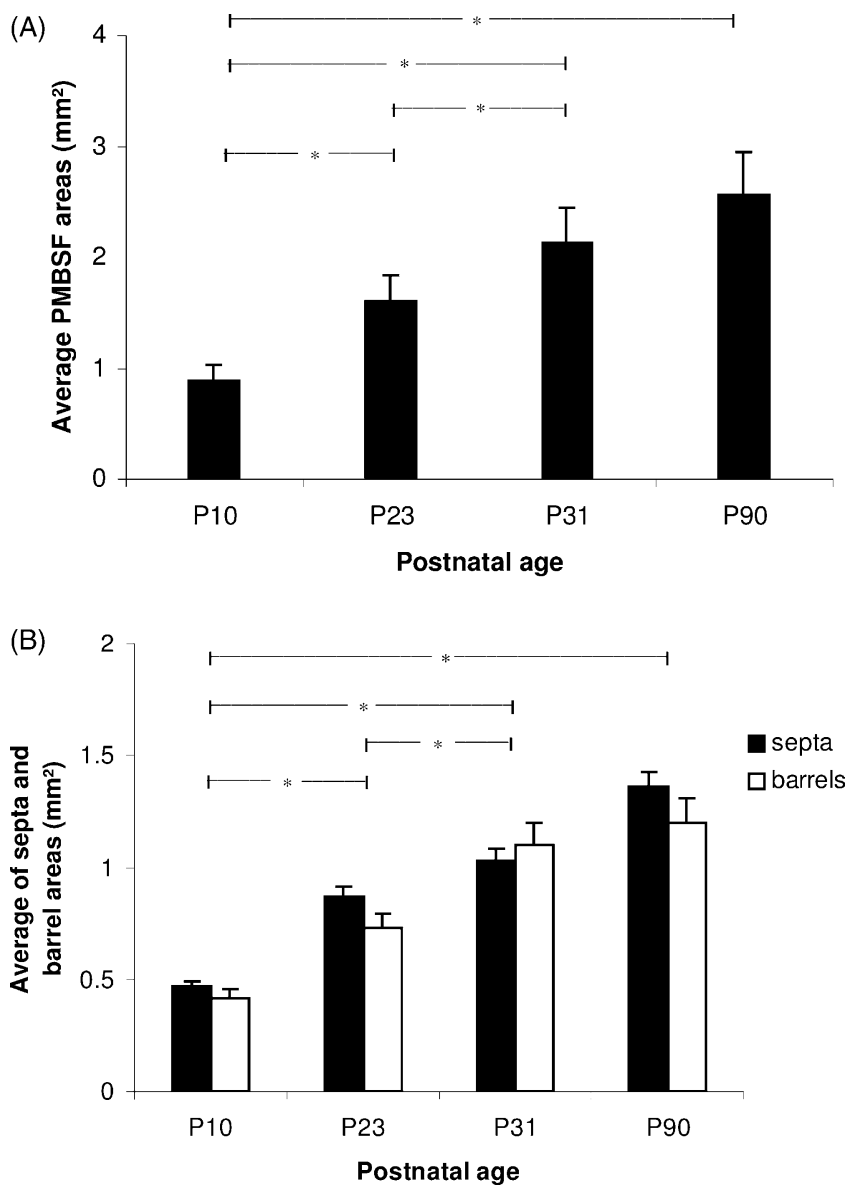

Fig. 3. Histograms showing PMBSF total areas $\left(\mathrm{mm}^{2}\right)$ and individual measurements of septal and barrel areas during development. Histogram A shows a progressive areal PMBSF increasing from P10 to P31. After P31 the total PMBSF area remained stable and did not differ in area from that in $\mathrm{P} 90\left({ }^{*} P<0.05\right)$. Histogram B shows that total individual barrel area did not differ $(P>0.05)$ from the septal area in a same age, in all ages analyzed (ANOVA/Newman-Keuls post hoc test). 

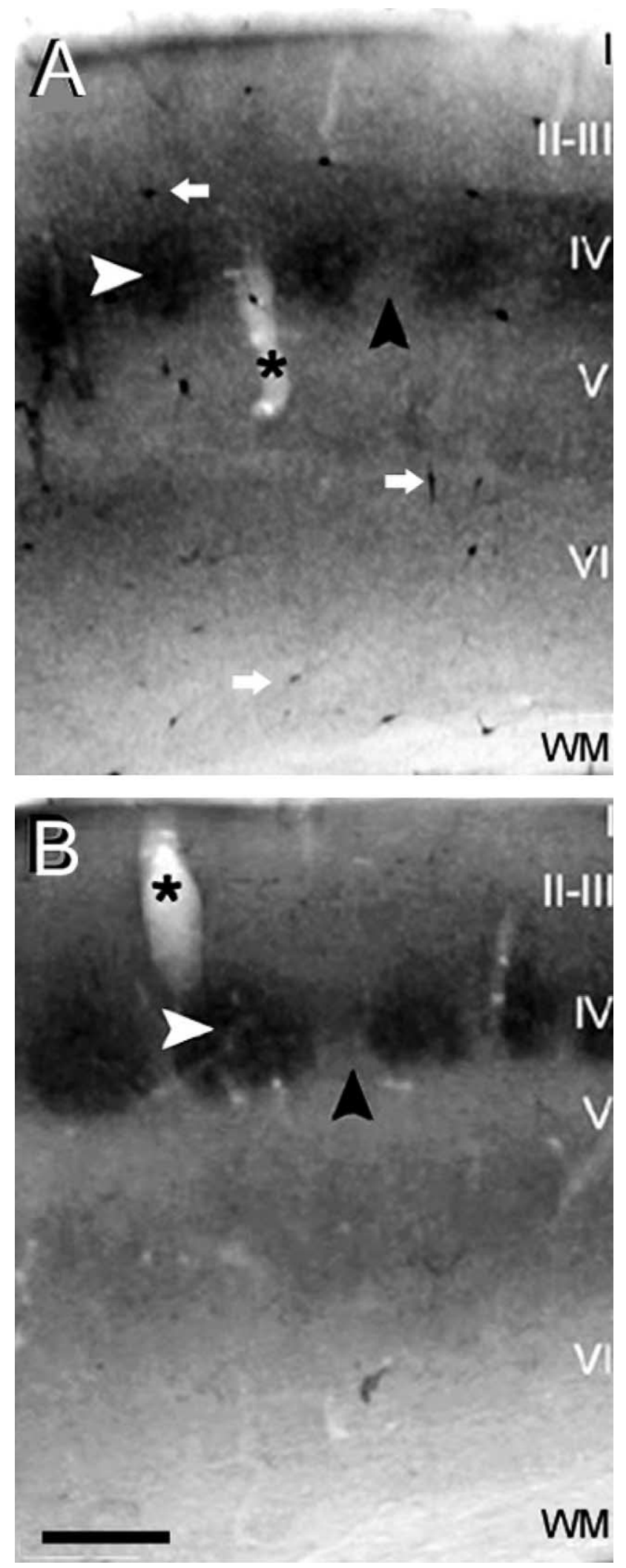

Fig. 4. Coronal view showing NADPH-d (A) and CO (B) distribution in adjacent sections of SI (P90). Note the similar distribution of both enzymes, which permit to define the six cortical layers. In A it is possible to see some type I NADPH-d neurons throughout layers (arrows). Arrowheads: white: example of barrel; black: septa. Asterisks: blood vessels. Scale bar: $200 \mu \mathrm{m}$. low reactivity, while layer VI presented a darker staining, making it rather easy to identify the limit between these two layers and with the underneath white matter (Fig. 4). In the white matter, both enzymes were distributed more homogeneously with considerably less reaction product than that seen in any other layer of the cortical gray matter (Fig. 4).

The laminar distribution of NADPH-d neurons was similar to that previously described in the literature (Leigh et al., 1990; Bravo et al., 1997; Vercelli et al., 1999). Bipolar and multipolar NADPH-d aspiny neurons could be seen scattered throughout the cortical layers (data not illustrated). Nevertheless, these cells were rarely seen in layer I, but a higher number of these cells were present in layers II-III, where their dendritic trees were oriented in both horizontal and vertical planes. In layer IV, the majority of NADPH-d neurons were found in the less reactive septa.

The NADPH-d cells were especially numerous around the limit between layer VI and white matter. Interestingly, some white matter cells, especially those present at the border with layer VI, projected their dendrites into the gray matter and their cell bodies were elongated, with their principal axes oriented in parallel to the limit between gray and white matters (Fig. 5). Similar findings have been described in the primary visual cortex of other rodent species (Costa et al., 1994). In addition, it was possible to see many small neurons weakly reactive for NADPH-d in all ages evaluated (see examples in the Fig. 6), especially in the layers II and III. These neurons presented poorly labeled-dendritic arbors. They are similar to type II NADPH-d neurons previously described in other species (Sandell, 1986; Franca et al., 1997; Franca et al., 2000; Wiencken and Casagrande, 2000).

There is a progressive modification in the complexity of the dendritic arborization of NADPH-d neurons during barrel field development (Fig. 7). In the earlier ages evaluated (P10-P14), only the cell bodies appeared highly reactive, without a prominent dendritic arbor (Fig. 7). In P23, the dendritic arbor of NADPH-d cells became more complex, displaying dendrites with both secondary and tertiary branches (Fig. 7). The adult pattern of dendritic ramification seemed to be fully established on P31 (Fig. 7). After this age it was not possible to see conspicuous modifications in cell morphology compared to that seen in mature animals (Fig. 7).

In the present study, type I NADPH-d neurons in septal regions seem to possess a more complex dendritic arborization than cells inside barrels, especially in more aged animals (Fig. 7).

In the sections submitted to double-labeling NADPHd/NOS, the NADPH-d type I neurons could be labeled with the anti-neuronal NOS antibody (Fig. 8). This confirms that type I NADPH-d neurons correspond to a cell population responsible for the synthesis of NO in the brain (see also: Hope et al., 1991; Dawson et al., 1991; Valtschanoff et al., 1993; Luth et al., 1995; Picanço-Diniz et al., 2004). For type II neurons, it was difficult to discern any pattern of double-labeling (Fig. 8). 


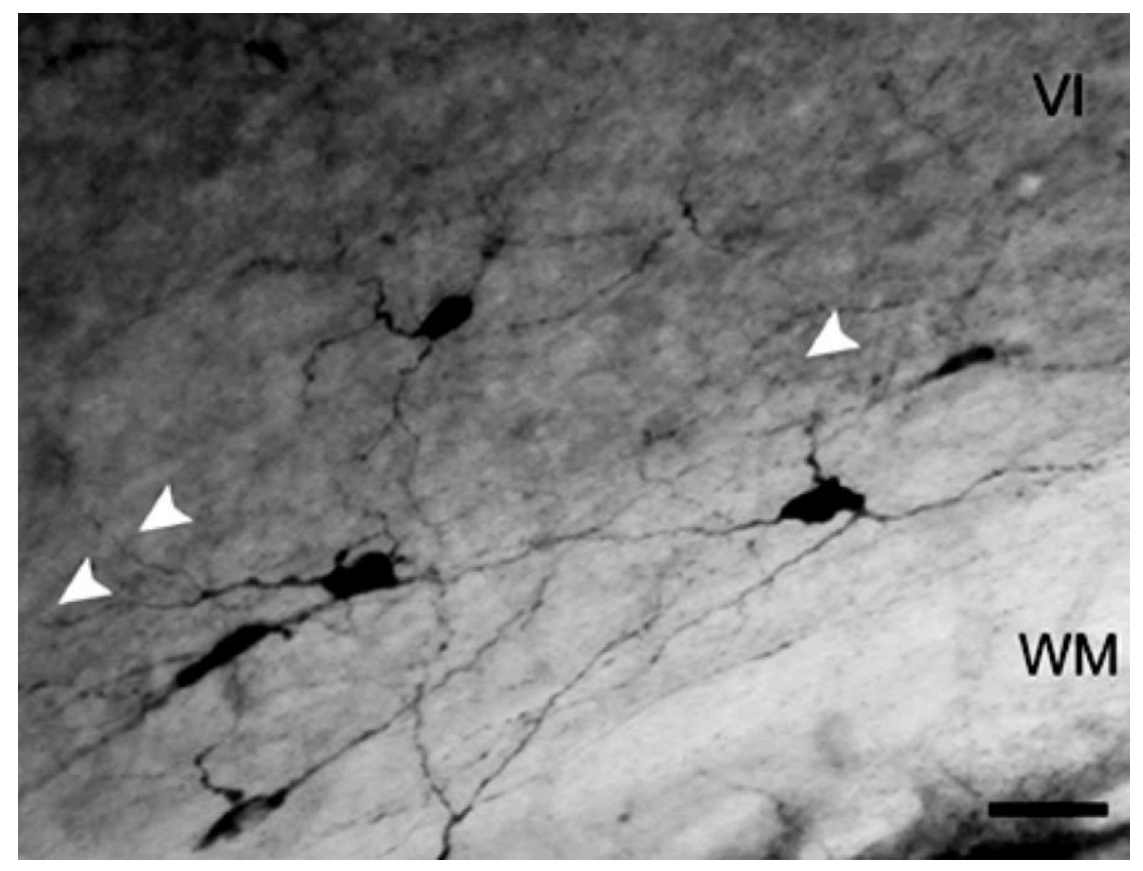

Fig. 5. Type I NADPH-d cells in the limit between gray and white matters. Note that some neurons whose cell bodies are located at the white matter send dendrites toward the gray matter (arrowheads). Scale bar: $30 \mu \mathrm{m}$.

\subsection{Morphometric analysis of the NADPH-d positive neurons}

NADPH-d neurons were present in both septa and barrels in all ages analyzed (see Fig. 7). Quantitative analysis of these neurons over the postnatal development $(\mathrm{P} 10, \mathrm{P} 23, \mathrm{P} 31, \mathrm{P} 90)$ revealed a significant increase $(P$ $<0.05)$ in the number of these cells from P10 to P23 (highest number of cells) in the PMBSF (Fig. 9). On the other hand, from P23 to P31 there was a significant decrease in the number of cells $(P<0.05)$. Nevertheless, from P31, the number of NADPH-d cells remained stable until P90 with no statistical differences between groups $(P>0.05)$. However, the number of NADPH-d neurons inside barrels was always lower than in septa (Fig. 9).

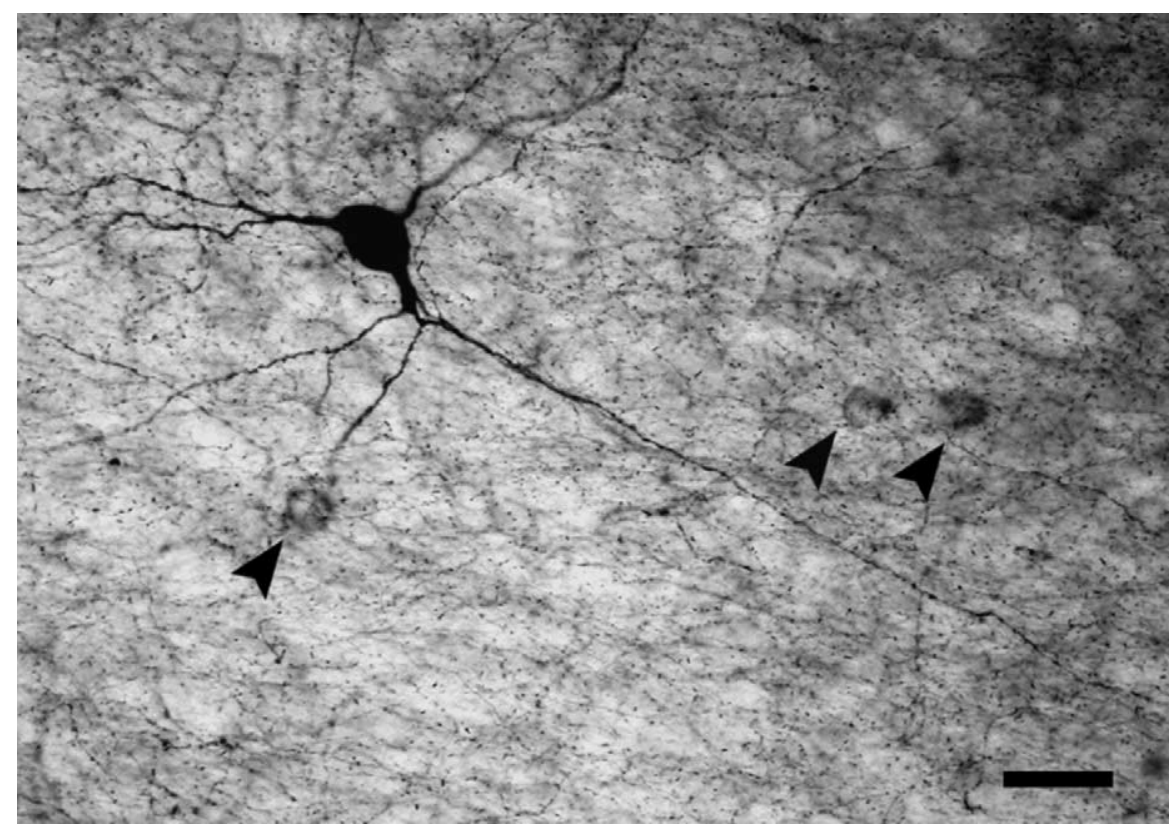

Fig. 6. Comparative morphology of types I and II neurons in the septal region of SI. Note the weakly stained dendritic arbor of type II neurons (arrowheads) when compared to that of type I cells. Scale bar: $30 \mu \mathrm{m}$. 

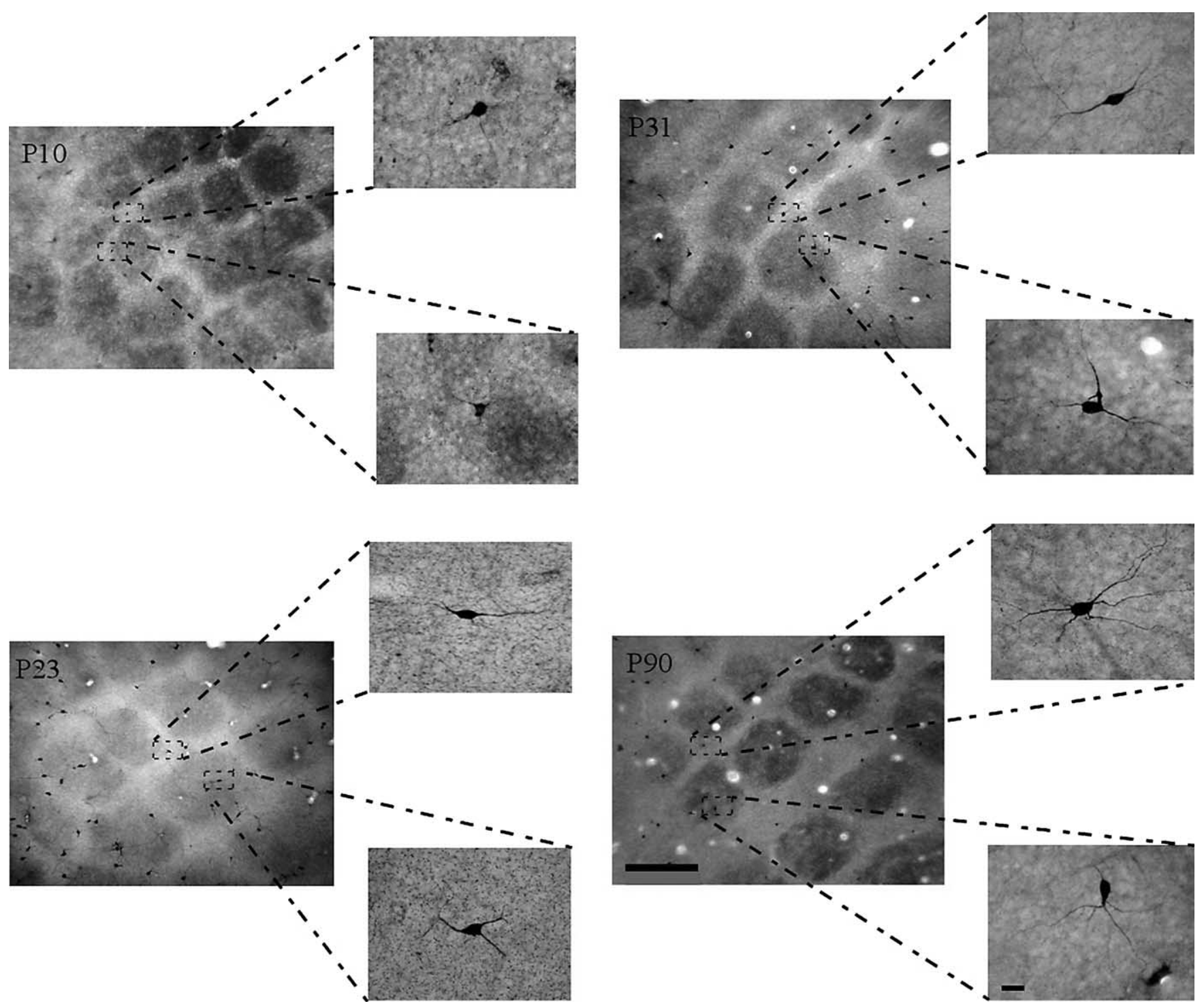

Fig. 7. Progressive modification of the dendritic morphology of type I neurons during PMBSF development. Note a progressive increase in the dendritic arbor from P10 to P31. There is no conspicuous morphological modification from P31 to adulthood (P90). Scale bars: $300 \mu \mathrm{m}$ (lower magnification); $200 \mu \mathrm{m}$ (enlargements).

\section{Discussion}

The main goal of this study was to use qualitative and quantitative methods to investigate the distribution of NADPH-d neurons in rat SI and the maturation of their morphology, as seen by the distribution of the NADPH-d reaction product, during the barrel field development. In addition, we evaluated the postnatal development of NADPH-d activity in neuropil during development of this CNS region.

\subsection{NADPH-d reactivity in the rat barrel field during development}

In all ages evaluated in the present study (from P10 to P90) the barrel field could be easily visualized by using either NADPH-d or CO histochemistries. These results disagree with previous studies which report a virtual dis- appearance of the NADPH-d activity in the rat barrels from P21 to adulthood (Vercelli et al., 1999) and also in the mouse barrel field, which became undetectable by the end of the second postnatal week (Mitrovic and Schachner, 1996). Such conflicting results may be explained by a range of methodological differences, from fixation procedures to the specific NADPH-d histochemistry method used. For instance, according to our experience, postfixative procedures trick NADPH-d histochemistry (see Pereira et al., 2000).

It is well known that NADPH-d activity in the brain can be altered by fixatives (Matsumoto et al., 1993). One can speculate that, during certain stages of postnatal development, NADPH-d activity is produced by enzymatic isoforms that are more sensitive to fixation. Nevertheless, the positive result obtained in this study reveals that NADPH-d activity in barrel cortex is unequivocally present during the whole postnatal development. In respect to the adult pattern, our 


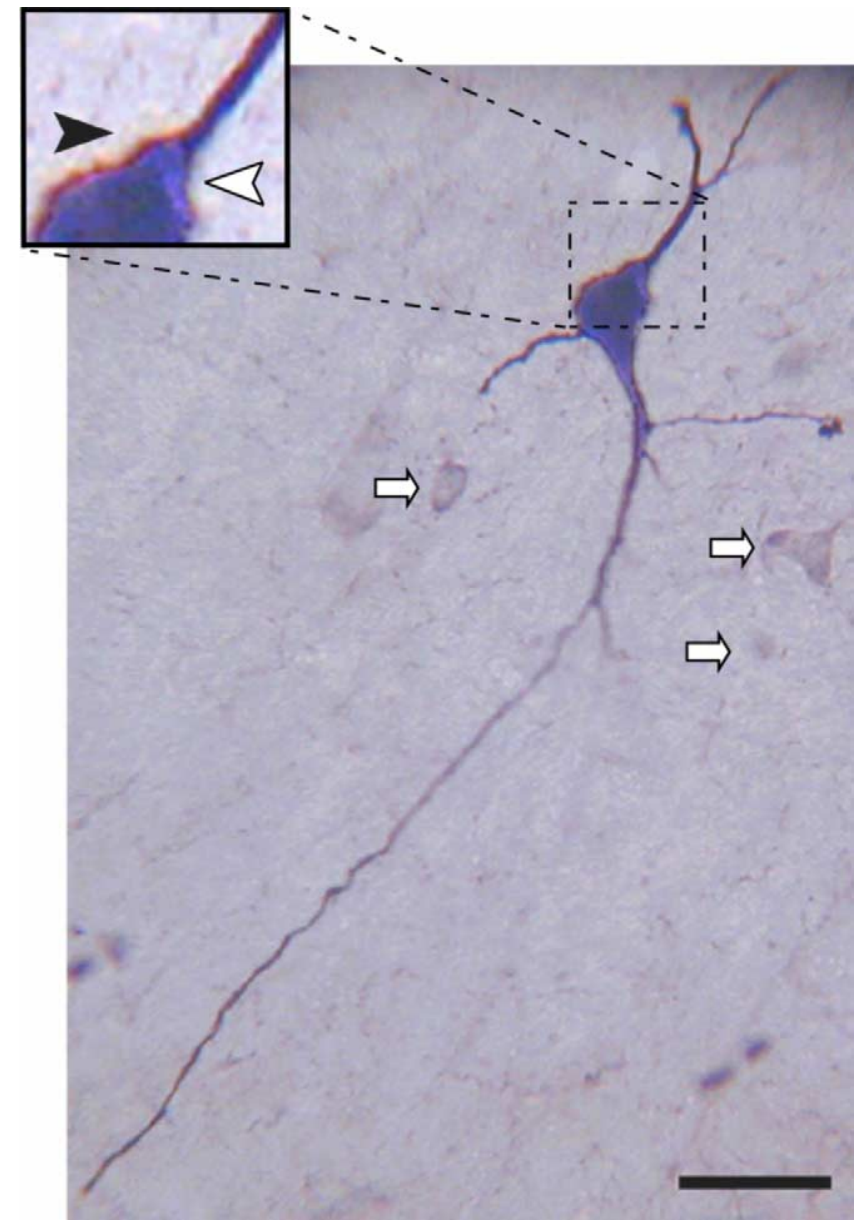

Fig. 8. Double-staining for NADPH-d and NOS in a type I neuron. The picture shows part of both dendrite and cell body stained in blue by NADPH-d histochemistry (white arrowhead) and labeled in brown by NOS immunohistochemistry (black arrowhead). Arrows point to type II cells. Scale bar: $25 \mu \mathrm{m}$.

results are in agreement with previous reports of our group, which have shown the presence of a NADPH-d-positive barrel field in rats and mice (Franca and Volchan, 1995; Franca et al., 2000; Pereira et al., 2000).
The pattern of NADPH-d reactivity in the barrel field was markedly similar in all ages evaluated in the present investigation. The enzymatic activity is segregated, though, so that the central regions of the barrels (hollows) appear as intensely stained patches, flanked by less reactive regions (septa). The barrel hollow is occupied by axon terminals arriving from thalamus (Kim and Ebner, 1999). The septa, on the other hand, are the target for callosal fibers coming from the opposite hemisphere (Koralek et al., 1990). It is possible that the NADPH-d/NO activity typical of barrel hollows can reflect the presence of NADPH-d-positive axon terminals in this region. This would be similar to thalamo-recipient layer of monkey primary visual cortex (layer IVC), where electron microscopy studies revealed that NADPH-d/NO reactivity is massively present in axonal terminals (Aoki et al., 1993).

\subsection{Distribution of the NADPH-d neurons during barrel field maturation}

The number of NADPH-d cells in PMBSF increased from P10 to P23, with a peak in the absolute number around the end of the third week/beginning of fourth week (P23). This result is similar to that described for other cortical regions, such as the prefrontal cortex (Tomic et al., 1994) and also for some subcortical regions, like hippocampus, lateral geniculate nucleus, and striatum (González-Hernandez et al., 1993; Moritz et al., 1999; Murata and Masuko, 2003). These findings suggest that, during the rat's postnatal development the same quantitative changes in the number of NADPH-d neurons in PMBSF occur simultaneously in other brain regions. Nevertheless, for some brain areas, such as caudate-putamen, Yan et al. (1994) have reported that the highest number of NADPH-d cells is found in an earlier time point (around P14), but they did not evaluate the cortical area which includes the somatosensory cortex.

Whether or not the evolution of NADPH-d activity in individual neurons is similar in all cortical areas, and what are regulating it are still open questions. Based in previous reports, which describe a heterogeneous distribution of

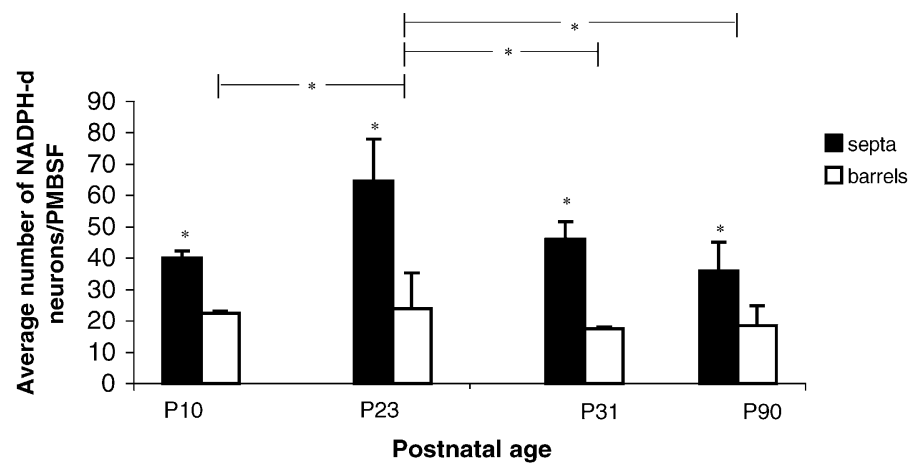

Fig. 9. Quantitative analysis of NADPH-d type I neurons during PMBSF development. For each animal, the number of neurons was counted from three tangential sections through layer IV (three animals per age), to certify that the whole vertical extension of the barrel field has been evaluated. There was a significant increase $\left({ }^{*} P<0.05\right)$ in the number of these cells from P10 to P23. Cell number decreased from P23 to P31 $\left({ }^{*} P<0.05\right.$, ANOVA/Newman-Keuls post hoc test-asterisks in the top of the horizontal bars). From P31, the number of type I NADPH-d cells remained stable until P90 $(P>0.05)$. The number of cells was always higher in septa than inside barrels in all ages evaluated ${ }^{*} P<0.05$, Student's $t$-test). 
NADPH-d in some parts of the rodent brain (Vincent and Kimura, 1992; Derer and Derer, 1993; Bidmon et al., 1997; Oermann et al., 1999; Franca et al., 2000), it is possible to hypothesize that there is an ontogenetic origin for the heterogeneous distribution of this cortical neuronal sub-population.

The pattern of distribution of NADPH-d neurons in the sub-compartments of the barrel field (septa and barrels) was markedly similar in all ages evaluated. The number of cells was always higher in septa than barrels. Such distribution is virtually similar to that described for other subgroups of interneurons, such as those immunoreactive to glutamic acid decarboxylase (GAD) and $\gamma$-aminobutyric acid (GABA) in the barrel field of small rodents (Lin et al., 1985; Chmielowska et al., 1986; Spreafico et al., 1988; Valtschanoff et al., 1993). Further studies are necessary to elucidate the physiological meaning of this differential distribution of the major neuronal groups in the barrel field.

In addition to their distribution, the morphology of NADPH-d neurons also appears to change noticeably during cortical maturation and seems to be well established around P23. The dendritic arbor of the neurons observed in P10-P14 is less complex than those seen in more aged animals (around P23 and until P90), for instance. These normal maturing events seem to be influenced by mechanisms dependent on NO (Harsanyi and Friedlander, 1997; Zhang et al., 2002; Fernández et al., 2003).

\subsection{Possible physiological functions of $N O$ in the barrel field}

NO is involved in the control of cerebral blood flow (Iadecola, 1993) and metabolism (Wong-Riley et al., 1998). Also, several studies have demonstrated that the brain retains the ability for plastic alterations during maturity (see Ebner et al., 1997 for a review). For instance, representation borders within the rodent somatosensory cortex can be relocated after intracortical electrical microstimulation (Spengler and Dinse, 1994). The high NADPH-d reactivity seen in the barrel field neuropil throughout the postnatal development suggests a role for NO in some physiological aspects of the cortical maturation. Some studies suggest that NO could be one of the molecules responsible for synaptic modifications observed during development (see Schumann and Madison, 1994 for review). The differential distribution of neuropil reactivity and NADPH-d neurons in the barrel sub-compartments (septa and hollows) could be correlated with the differential physiological properties of both regions (see Kim and Ebner, 1999).

It seems unclear why interneurons locate preferentially in the septal regions. However, it is important to considerate the differential NADPH-d reactivity in neuropil of septa and barrels and their relationship with NADPH-d neurons distribution. Our results point to a low activity of nitric oxide in septal neuropil. We can hypothesize that the highest number of NADPH-d cell bodies in septa could be "compensating" the lower quantity of NO dispersed in neuropil, since NADPH-d cells are an important source of NO in the CNS.

\subsection{Conclusions}

We present evidence that the enzymatic activity of NADPH-d remains high in the rat somatosensory system since P10 until adulthood, forming barrel fields that are well correlated with $\mathrm{CO}$ activity. In addition, our results show that the progressive changes in both morphology and number of NADPH-d neurons seem to occur at the same time window during barrel field maturation. Besides, distribution of NADPH-d cells in the barrel field seems to correlate with the distribution of these cells in some other regions of the developing rat brain. Further studies, using NOS-specific inhibitors or NOS knockout models to evaluate the expression of the NADPH-d/NO during the period of barrel field maturation, should investigate whether or not NO plays a role on the mechanisms of barrel field formation.

\section{Acknowledgements}

This study was part of a dissertation submitted to UFPA Biological Science Post-Graduation Department as one of the requirements for the Master's Degree of Marco Aurélio M. Freire. Study supported by grants from Coordenação de Aperfeiçoamento de Pessoal de Nível Superior (CAPES) and Conselho Nacional de Desenvolvimento Científico e Tecnológico (CNPq). Thanks go to Mr. Dennyson de Faria for help in some experiments.

\section{References}

Aoki, C., Fenstermaker, S., Lubin, M., Go, G.G., 1993. Nitric oxide synthase in the visual cortex of monocular monkeys as revealed by light and electron microscopic immunocytochemistry. Brain Res. 620, 97-113.

Bidmon, H.J., Wu, J., Godecke, A., Schleicher, A., Mayer, B., Zilles, K., 1997. Nitric oxide synthase-expressing neurons are area-specifically distributed within the cerebral cortex of the rat. Neuroscience 81, 321-330

Bravo, H., Inzunza, O., Fernandez, V., Sanhueza, M., 1997. Distribution of NADPH-d positive neurons during postnatal development of the rat somatosensory cortex correlates with gradients of neurogenesis and development. Neurosci. Lett. 234, 103-106.

Chmielowska, J., Stewart, M.G., Bourne, R.C., Hamori, J., 1986. $\gamma$-Aminobutyric acid immunoreactivity in mouse barrel field: a light microscopical study. Brain Res. 368, 371-374.

Contestabile, A., 2000. Roles of NMDA receptor activity and nitric oxide production in brain development. Brain Res. Rev. 32, 476-509.

Costa, E.T., do-Nascimento, J.L.M., Picanço-Diniz, C.W., Quaresma, J.A.S., Silva, M., 1994. Histochemical characterization of NADPH-diaphorase activity in area 17 of diurnal and nocturnal primates and rodents. Braz. J. Med. Biol. Res. 29, 1355-1362.

Dawson, T.M., Bredt, D.S., Fotuhi, M., Hwang, P.M., Snyder, S.H., 1991. Nitric oxide synthase and neuronal NADPH diaphorase are identical in brain and peripheral tissues. Proc. Natl. Acad. Sci. U.S.A. 88, 7797-7801. 
Derer, P., Derer, M., 1993. Ontogenesis of NADPH-diaphorase neurons in the mouse forebrain. Neurosci. Lett. 152, 21-24.

Ebner, F.F., Rema, V., Sachdev, R., Symons, F.J., 1997. Activity-dependent plasticity in adult somatic sensory cortex. Semin. Neurosci. 9, 47-58.

Estevez, A.G., Spear, N., Manuel, S.M., Radi, R., Henderson, C.E., Barbeito, L., Beckman, J.S., 1998. Nitric oxide and superoxide contribute to motor neuron apoptosis induced by trophic factor deprivation. J. Neurosci. 18, 923-931.

Fernández, A.P., Alonso, D., Lisazoaín, I., Serrano, J., Leza, J.C., Bentura, M.L., López, J.C., Encinas, J.M., Fernández-Vizarra, P., Castro-Blanco, S., Martínez, A., Martinez-Murillo, R., Lorenzo, P., Pedrosa, J.A., Peinado, M.A., Rodrigo, J., 2003. Postnatal changes in the nitric oxide system of the rat cerebral cortex after hypoxia during delivery. Dev. Brain Res. 142, 177-192.

Franca, J.G., Volchan, E., 1995. NADPH diaphorase histochemistry as a marker for barrels in rat somatosensory cortex. Braz. J. Med. Biol. Res. 28, 787-790.

Franca, J.G., Volchan, E., Jain, N., Catania, K.C., Oliveira, R.L.S., Hess, F.F., Jablonka, M., Rocha-Miranda, C.E., Kaas, J.H., 2000. Distribution of NADPH diaphorase cells in visual and somatosensory cortex in four mammalian species. Brain Res. 864, 163-175.

Franca, J.G., do-Nascimento, J.L.M., Picanço-Diniz, C.W., Quaresma, J.A.S., Silva, A.L.C., 1997. NADPH-diaphorase activity in area 17 of the squirrel monkey visual cortex: neuropil pattern, cell morphology and laminar distribution. Braz. J. Med. Biol. Res. 30, 1093-1105.

Gabbott, P.L.A., Bacon, S.J., 1995. Co-localisation of NADPH diaphorase activity and GABA immunoreactivity in local circuit neurones in the medial prefrontal cortex (mPFC) of the rat. Brain Res. 699, 321-328.

Glassman, R.B., 1994. Behavioral effects of SI versus SII cortex ablations on tactile orientation-localization and postural reflexes of rats. Exp. Neurol. 125, 125-133.

Gomes-Leal, W., Silva, S.G.J., Oliveira, R.B., Picanço-Diniz, C.W., 2002. Computer-assisted morphometric analysis of intrinsic axon terminals in the supragranular layers of cat striate cortex. Anat. Embryol. 205, 291-300.

González-Hernandez, T., Conde-Sendin, M., Gonzalez-Gonzalez, B., Mantolan-Sarmiento, B., Perez-Gonzalez, H., Meyer, G., 1993. Postnatal development of NADPH-diaphorase activity in the superior colliculus and the ventral lateral geniculate nucleus of the rat. Dev. Brain Res. 76, 141-145.

Harsanyi, K., Friedlander, M.J., 1997. Transient synaptic potentiation in the visual cortex. 1: Cellular mechanisms. J. Neurophysiol. 77, 12691283.

Hope, B.T., Michael, G.J., Knigge, K.M., Vincent, S.R., 1991. Neuronal NADPH diaphorase is a nitric oxide synthase. Proc. Natl. Acad. Sci. U.S.A. $88,2811-2814$.

Iadecola, C., 1993. Regulation of the cerebral microcirculation during neural activity: is nitric oxide the missing link? Trends Neurosci. 16, 206-214.

Killackey, H.P., Rhoades, R.W., Bennett-Clarke, C.A., 1995. The formation of a cortical somatotopic map. Trends Neurosci. 18, 402-407.

Kim, U., Ebner, F.F., 1999. Barrels and septa: separate circuits in rat barrels field cortex. J. Comp. Neurol. 408, 489-505.

Koralek, C.A., Olavarria, J., Killackey, H.P., 1990. Areal and laminar organization of cortical projections in the rat somatosensory cortex. J. Comp. Neurol. 299, 133-150.

Leigh, P.N., Connick, J.H., Stone, T.W., 1990. Distribution of NADPH diaphorase positive cells in the rat brain. Comp. Biochem. Physiol. 97, 259-264.

Lin, C.S., Lu, S.M., Schmechel, D.E., 1985. Glutamic acid decarboxylase immunoreactivity in layer IV of barrel cortex of the rat and mouse. J. Neurosci. 5, 1934-1939.

Luebke, J.I., Weider, J.M., McCarley, R.W., Greene, R.W., 1992. Distribution of NADPH-diaphorase positive somata in the brainstem of the monitor lizard Varanus exanthematicus. Neurosci. Lett. 148, 129-132.

Luth, H.J., Hedlich, A., Hilbig, H., Winkelmann, E., Mayer, B., 1994. Morphological analyses of Nadph-diaphorase nitric-oxide synthase positive structures in human visual-cortex. J. Neurocytol. 23, 770782.

Luth, H.J., Hedlich, A., Hilbig, H., Winkelmann, E., Mayer, B., 1995. Postnatal development of NADPH-diaphorase/nitric oxide synthase positive nerve cells in the visual cortex of the rat. J. Hirnforsch. 36, 313-328.

Matsumoto, T., Nakane, M., Pollock, J.S., Kuk, J.E., Förstermann, U., 1993. A correlation between soluble brain nitric oxide synthase and NADPH-diaphorase activity is only seen after exposure of the tissue to fixative. Neurosci. Lett. 155, 61-64.

Melzer, P., Smith, C.B., 1998. Plasticity of cerebral metabolic whisker maps in adult mice after whisker follicle removal. I. Modifications in barrel cortex coincide with reorganization of follicular innervation. Neuroscience 83, 27-41.

Mitrovic, N., Schachner, M., 1996. Transient expression of NADPH diaphorase activity in the mouse whisker to barrel field pathway. J. Neurocytol. 25, 429-447.

Moritz, G.C., Tenorio, F., Allodi, S., Mendez-Otero, R., 1999. Expression of nitric oxide synthase in the developing rat hippocampus. Neurosci. Lett. 263, 89-92.

Mountcastle, V.B., 1997. The columnar organization of the neocortex. Brain 120, 701-722.

Murata, Y., Masuko, S., 2003. Developing patterns of nitric oxide synthesizing neurons in the rat striatum: histochemical analysis. Dev. Brain Res. 141, 91-99.

Oermann, E., Bidmon, H.J., Mayer, B., Zilles, K., 1999. Differential maturation of nitric oxide synthase-I and NADPH diaphorase in functionally distinct cortical areas of the mouse cerebral cortex. Anat. Embryol. 200, 27-41.

Pereira Jr., A., Freire, M.A.M., Pacheco-Bahia, C., Franca, J.G., Picanço-Diniz, C.W., 2000. The barrel field of the adult mouse SmI cortex as revealed by NADPH diaphorase histochemistry. Neuroreport $11,1889-1892$.

Picanço-Diniz, C.W., Boche, D., Gomes-Leal, W., Perry, V.H., Cunningham, C., 2004. Neuropil and neuronal changes in hippocampal NADPH-diaphorase histochemistry in the ME7 model of murine prion disease. Neuropathol. Appl. Neurobiol. 30, 292-303.

Rice, F.L., 1995. Comparative aspects of barrel structure and development. In: Jones, E.G., Diamond, I.T. (Eds.), The Barrel Cortex of Rodents, Cerebral Cortex, vol. 11. Plenum Press, New York, pp. 1-75.

Rice, F.L., van der Loos, H., 1977. Development of the barrels and barrel field in the somatosensory cortex of the mouse. J. Comp. Neurol. 171, $545-560$.

Samama, B., Chateau, D., Boehm, N., 1995. Expression of NADPHdiaphorase in the rat forebrain during development. Neurosci. Lett. 184, 204-207.

Sandell, J.H., 1986. NADPH diaphorase histochemistry in the macaque striate cortex. J. Comp. Neurol. 251, 388-397.

Scherer-Singler, V., Vincent, S.R., Kimura, H., Mcgeer, F.G., 1983. Demonstration of a unique population of neurons with NADPH diaphorase histochemistry. J. Neurosci. Methods 9, 229-234.

Schumann, E.M., Madison, D.V., 1994. Nitric oxide and synaptic function. Ann. Rev. Neurosci. 17, 153-183.

Shu, S.Y., Ju, G., Fan, L.Z., 1988. The glucose-oxidase dab nickel method in peroxidase histochemistry of the nervous system. Neurosci. Lett. 85, 169-171.

Spengler, F., Dinse, H.R., 1994. Reversible relocation of representational boundaries of adult rats by intracortical microstimulation. Neuroreport 5, 949-953.

Spreafico, R., De Biasi, S., Frassoni, C., Battaglia, G., 1988. A comparison of GAD- and GABA-immunoreactive neurons in the first somatosensory area (SI) of the rat cortex. Brain Res. 474, 192-196.

Thomas, E., Pearse, A.G.E., 1961. The fine localization of dehydrogenases in the nervous system. Histochemistry 2, 266-282.

Tomic, D., Zobundzija, M., Meaugorac, M., 1994. Postnatal development of nicotinamide adenine dinucleotide phosphate diaphorase 
(NADPH-d) positive neurons in rat prefrontal cortex. Neurosci. Lett. 170, 217-220.

Valtschanoff, J.G., Weinberg, R.J., Kharazia, V.N., Schmidt, H.H.H.W., Nakane, M., Rustioni, A., 1993. Neurons in rat cerebral cortex that synthesize nitric oxide: NADPH diaphorase histochemistry. NOS immunocytochemistry and colocalization with GABA. Neurosci. Lett. 157, 157-161.

van der Loos, H., Woolsey, T.A., 1973. Somatosensory cortex: structural alterations following early injury to sensory organs. Science 179, 395 398.

Vercelli, A., Repici, M., Biasiol, S., Jhaveri, S., 1999. Maturation of NADPH-d activity in the rat's barrel-field cortex and its relationship to cytochrome oxidase activity. Exp. Neurol. 156, 294-315.

Vincent, S.R., Kimura, H., 1992. Histochemical mapping of nitric-oxide synthase in the rat-brain. Neuroscience 46, 755-784.

Wallace, M.N., 1987. Histochemical demonstration of sensory maps in the rat and mouse cerebral cortex. Brain Res. 418, 178-182.

Wallace, M.N., Tayebjee, M.H., Rana, R.S., Farquhar, D.A., Nyong, A.O., 1996. Pyramidal neurones in pathological human motor cortex express nitric oxide synthase. Neurosci. Lett. 212, 187-190.

Welker, C., 1971. Microelectrode delineation of fine grain somatotopic organization of SI cerebral cortex in albino rat. Brain Res. 26, 259275 .

Wiencken, A.E., Casagrande, V.A., 2000. The distribution of NADPH diaphorase and nitric oxide synthetase (NOS) in relation to the functional compartments of areas V1 and V2 of primate visual cortex. Cereb. Cortex 10, 499-511.

Wong-Riley, M.T.T., Welt, C., 1980. Histochemical changes in cytochrome oxidase of cortical barrel of the vibrissal removal in neonatal and adult mice. Proc. Natl. Acad. Sci. U.S.A. 77, 2333-2337.
Wong-Riley, M.T.T., 1989. Cytochrome oxidase: an endogenous metabolic marker for neuronal activity. Trends Neurosci. 12, 94-101.

Wong-Riley, M.T.T., 1979. Changes in the visual-system of monocularly sutured or enucleated cats demonstrable with cytochrome-oxidase histochemistry. Brain Res. 171, 11-28.

Wong-Riley, M.T.T., Anderson, B., Liebl, W., Huang, Z., 1998. Neurochemical organization of the macaque striate cortex: Correlation of cytochrome oxidase with $\mathrm{Na}(+) \mathrm{K}(+)$ ATPase, NADPH-diaphorase, nitric oxide synthase, and $N$-methyl-D-aspartate receptor subunit 1 . Neuroscience 83, 1025-1045.

Wong-Riley, M.T.T., Welt, C., 1980. Histochemical changes in cytochrome oxidase of cortical barrel of the vibrissal removal in neonatal and adult mice. Proc. Natl. Acad. Sci. U.S.A. 77, 2333-2337.

Woolsey, T.A., van der Loos, H., 1970. The structural organization of layer IV in the somatosensory region (SI) of mouse cerebral cortex: the description of a cortical field composed of discrete cytoarchitectonic units. Brain Res. 17, 205-242.

Yan, X.X., Garey, L.J., 1997. Morphological diversity of nitric oxide sythesising neurons in mammalian cerebral cortex. J. Hirnforsch. 38, $165-172$.

Yan, X.X., Garey, L.J., Jen, L.S., 1994. Development of NADPHdiaphorase activity in the rat neocortex. Dev. Brain Res. 79, 29-38.

Zhang, Y.T., Zhang, D.L., Cao, Y.L., Zhao, B.L., 2002. Developmental expression and activity variation of nitric oxide synthase in the brain of golden hamster. Brain Res. Bull. 58, 385-389.

Zilles, K., Wree, A., 1985. Cortex: areal and laminar structure. In: Paxinos, G. (Ed.), Forebrain and Midbrain. Academic Press, New York, Harcourt Brace Jovanovic, pp. 375-415. 